\title{
Measuring, Adjusting, And Forecasting Beta: The Case Of All The Lebanese Listed Firms
}

Viviane Y. Naïmy, (Email: vnaimy@aud.edu), American University in Dubai, UEA

\begin{abstract}
Beta is commonly used in many publications as a measure of risk of an investment or as an index for safety. Such a risk assessment has never been done for the Lebanese stock market. This paper presents the alternative types of models for estimating future correlation coefficients and the sources of their forecast errors. Betas of all the Lebanese listed firms are measured and a special tailored adjustment technique is conceived to fit their constraints.
\end{abstract}

\section{INTRODUCTION}

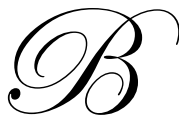

eta measures risk. Actually, it measures the risk of individual assets, an inefficient portfolio as well as an efficient portfolio. The primary conclusion of the CAPM ${ }^{1}$ is that the relevant risk of an individual stock, called beta, is the amount of risk the stock contributes to a well-diversified portfolio. Beta is commonly used in many publications as a measure of risk of an investment or as an index for safety. Since there is a complete absence of academic work measuring betas of the Lebanese listed firms on the Beirut Stock Exchange (BSE), this paper tries to measure betas and adjust them using a particular tailored qualitative/quantitative adjustment technique. Beyond discussions on the pertinence of beta as being a good measure of risk or not, this paper constitutes a benchmark for investors and creditors wishing to quantify risk and a solid base for future researches.

The first section presents the concept of beta and the alternative types of models for estimating future correlation coefficients. Section two investigates the sources of forecast errors of extrapolated beta coefficients and three recommended adaptive/adjustment procedures for improving beta forecasts. The third section is devoted to measuring and adjusting betas of the listed Lebanese firms. For this purpose, we build two different market indexes and test them in order to select the appropriate one for the application of the Market Model. Then, betas are calculated and adjusted according to a special tailored technique to convene the Lebanese firms' constraints.

\section{THE CONCEPT OF BETA}

\section{The Meaning Of Beta}

Beta measures the co-movement of the return on Asset $i$ and the return on the market portfolio. The beta of Asset $i$, denoted by $\beta_{\mathrm{i}}$, is defined in the literature on the CAPM as

$\beta_{\mathrm{i}}=\operatorname{Cov}\left(\mathrm{R}_{\mathrm{i}}, \mathrm{R}_{\mathrm{m}}\right) / \sigma_{\mathrm{m}}^{2}=\left(\sigma_{\mathrm{i}} / \sigma_{\mathrm{m}}\right) \rho_{\mathrm{im}} \quad 2$

where $\mathrm{R}_{i}$ is the rate of return on the $i$ th asset, $\mathrm{R}_{\mathrm{m}}$ is the rate of return on the market portfolio, and Cov is the covariance between $i$ th asset and the market. $\sigma_{\mathrm{m}}$ is the standard deviation of the market's return.

\footnotetext{
${ }^{1}$ Fama E. and French K. (1996), The CAPM Is Wanted Dead or Alive, Journal Of Finance, Vol. 51, No. 5, December, pp. 19471958.

${ }^{2}$ This equation indicates that a stock with a high standard deviation, $\sigma_{i}$, will tend to have high beta. This makes sense, because if all other things are equal, a stock with high stand-alone risk will contribute a lot of risk to the portfolio. Note too that a stock with a high correlation with the market, will also have a large beta, hence be risky. This also makes sense, because a high correlation means that diversification is not helping much, hence the stock contributes a lot of risk to the portfolio.
} 
With historical data when equal probability is assigned to each period, beta can be expressed as follows:

$$
\beta i=\frac{\frac{1}{N}\left(\sum_{t=1}^{N} R_{i, t^{\times}} R_{m, t}\right)-\overline{\mathrm{R}}_{i} \overline{R_{m}}}{\frac{1}{N}\left(\sum_{t=1}^{N} R_{m, t}^{2}\right)-\overline{R_{m}^{2}}}
$$

where $N$ denotes the number of observations and $t$ denotes historical periods. Obviously, beta also can be calculated for portfolios (efficient and inefficient alike) and mutual funds. The beta coefficient used by investors should reflect the expected volatility of a given stock's return versus the return on the market during some future period.

\section{Alternative Models For Estimating Future Correlation Coefficients}

\section{A Historical Model}

The simplest method is to assume that past values of the correlation coefficients are the best estimates of their future values. In short, calculate each pair-wise correlation coefficient over a historical period and use this value as an estimate of the future. No assumption is made as to how or why securities move together. Instead, the amount of their co-movement is estimated directly. Several studies ${ }^{3}$ have shown that while there is useful information contained in historical correlation coefficients, other techniques perform better. Historical matrix are usually used because it is common to all studies ${ }^{4}$ and can usefully serve as a benchmark against which other techniques can be evaluated.

\section{Single Index Models}

The single index model is the most widely used method of estimating correlation coefficients. As is well known, the key assumption underlying its use is that securities systematically move together only because of a common response to a single index. The most important variants of this model are:

\section{Unadjusted Betas}

Unadjusted betas are the betas obtained from a least square regression of security returns on a market index during some historical period. These betas are then used to estimate future correlation coefficients. Throughout this study we build our own price index adjusted for stock splits and for dividends in order to compute unadjusted betas by fitting a regression using monthly data covering the period 1999-2003.

\section{$\underline{\text { Vasicek Adjustment To Betas }}$}

The Vasicek ${ }^{5}$ procedure consists of taking a weighted average of the unadjusted beta and the leverage beta for the sample of stocks under consideration. The weights add to one and depend on the standard error of the individual beta and the standard deviation of the distribution of betas in the sample. We will not use the Vasicek

\footnotetext{
${ }^{3}$ Elton E. and Gruber M. (1973), Estimating the Dependence Structure of Share Prices, The Journal Of Finance. December, Vol. 33, No. 5, pp. 1203-1232

Jegadeesh N. and Titman S. (1993), Returns to Buying Winners and Selling Losers: Implications for Stock Market Efficiency. The Journal of Finance, March .pp. 69-91.

Odean T. (1998), Are Investors Reluctant To Realize Their Losses?, Journal Of Finance., October. pp. 1775-1798.

${ }^{4}$ Elton E., Gruber M., Urich T., (1978), Are Betas Best?, The Journal Of Finance, December, pp. 1375-1384.

${ }^{5}$ Vascicek O., (1973), A Note on Using Cross-Sectional Information in Bayesian Estimation of Security Betas. The Journal Of Finance, December, pp. 1233-1239.
} 
procedure in our study since the Lebanese financial market does not require, at this stage, such sophisticated adjustment. Other adjustments are to be applied throughout this paper (see section 3).

\section{Blume's Beta Adjustment}

The Blume ${ }^{6}$ adjustment procedure consists of regressing betas from one historical period and then using this regression to adjust betas for the forecast period. Consider three sequential five year periods of data:

- $\quad$ Unadjusted betas from the second period are regressed on unadjusted betas from the first period.

- Unadjusted betas from the second period are then substituted into this regression, as the independent variable to obtain an adjusted estimate of the beta in the third period.

\section{$\underline{\text { Assumed Beta Of One For All Stocks }}$}

The final estimate of beta was obtained by assuming that all betas are one. The use of a beta of one was motivated by Fisher ${ }^{7}$ and Kamin's finding that this naïve forecast performed surprisingly well compared to some more sophisticated techniques.

Using standard symbols, estimates of correlation coefficients are obtained from betas by noting that

$$
\operatorname{Cov}(i j)=\rho_{i j} \sigma_{i} \sigma_{j}=\beta_{i} \beta_{j} \sigma_{m}^{2}
$$

Thus,

$\rho_{i j}=\frac{\beta_{i} \beta_{j} \sigma_{m}^{2}}{\sigma_{i} \sigma_{j}}$

\section{Constant Correlation Model}

An alternative to the single index models is to assume that historical data only contains information concerning the mean correlation coefficients and that observed pair-wise differences from the average are random or sufficiently unstable, so that zero is a better estimate of their future value. The most aggregate averaging possible is to set every correlation coefficient equal to the average of all correlation coefficients. This technique is also called Overall Mean ${ }^{8}$.

\section{PREDICTION ERRORS AND ADJUSTMENT PROCEDURES}

\section{The Source Of Forecasting Errors}

The tests of beta forecast ${ }^{9}$ accuracy make use of the mean square error as a measure of forecast error. Mean square forecast error, MSE, is defined as follows:

\footnotetext{
${ }^{6}$ Blume M. (1971), On The Assessment of Risk, The Journal Of Finance, March, pp. 1-10.

${ }^{7}$ Fisher L., and Kamin J., (1991), Good Betas and Bad Betas, Paper for the Seminar on the Analysis of Security Prices, University of Chicago.

${ }^{8}$ According to Gruber M., this model was among the models that produced the best forecasts, outperforming the unadjusted beta and full historical model.

${ }^{9}$ Ziebart D., (1985), Control of Beta Reliability in Studies of Abnormal Return Magnitudes: A Methodological Note, The Journal of Accounting Research, Autumn, pp. 920-926.
} 
$M S E=\frac{1}{m} \sum_{j=1}^{m}\left(A_{j}-P_{j}\right)^{2}$

where:

$\mathrm{m}$ is the number of predictions contained in the forecast,

$\mathrm{P}_{j}$ is the estimated beta coefficient of security $\mathrm{j}$, and

$\mathrm{A}_{j}$ is the estimated beta coefficient of security $\mathrm{j}$.

In terms of the beta forecast, $\mathrm{P}_{j}$ represents the computed beta for the current period used as the predictor of beta for the subsequent period and $\mathrm{A}_{j}$ is the corresponding estimated beta for the subsequent period. MSE was chosen over alternative measures of forecast error because of its statistical tractability and because it can be easily partitioned into three components of forecast error as follows:

$M S E=(\bar{A}-\bar{P})^{2}+\left(1-\beta_{1}\right)^{2} S_{p}^{2}+\left(1-r_{A P^{2}}\right) S_{A^{2}}$

where:

$\bar{A}$ and $\bar{P}$ are the means of the realizations and predictions respectively;

$\beta_{1}$ is the slope coefficient of the regression of $\mathrm{A}$ on $\mathrm{P}$;

$S_{p}^{2}$ and $S_{A}^{2}$ are the sample variances in $\mathrm{P}$ and A respectively;

$r_{A P^{2}}$ is the coefficient of determination for $\mathrm{P}$ and $\mathrm{A}$.

The first term in equation (6) represents bias. Bias in a forecast indicates that the average prediction was either over or under the average realization. The second term represents inefficiency that illustrates a tendency for the prediction errors to be positive at low values of $\mathrm{P}_{j}$ and negative at high values of $\mathrm{P}_{j}$ as measured in equation (5). The final term is the random disturbance of MSE which contains those forecast errors not related to the value of the predictor, $\mathrm{P}_{j}$, or the predicted, $\mathrm{A}_{j}$.

The tests of beta forecast accuracy involved beta coefficients computed using the familiar market model:

$\tilde{R}_{j t}=\alpha_{j}+\beta_{j}\left(\tilde{R}_{m t}\right)+\widetilde{\varepsilon}_{j t}$

where:

$\widetilde{R}_{j t}$ is the return on security or portfolio $j$ in month $\mathrm{t}$,

$\widetilde{R}_{m t}$ is the temporally corresponding market return,

$\alpha_{j}$ is a parameter whose value is such that $\mathrm{E}\left(\varepsilon_{j t}\right)=0$

$\beta_{j}$ is defined in equation (1).

$\varepsilon_{j t}$ is a random error term, and the tildes denote random variables. 


\section{Adjusting Equations} coefficients.

Many attempts have been made to correct for inefficiency in beta forecasts by adjusting computed beta

First Procedure

As mentioned above, Blume's adjustment procedure consists of a simple linear regression of beta for security $j$ in period $2, \beta_{j 2}$, on the corresponding coefficient for period $1, \beta_{j 1}$ :

$\widetilde{\beta}_{j 2}=\delta_{0}+\delta_{1} \widetilde{\beta}_{j 1}+\widetilde{\varepsilon}_{j}$ for $j=1,2, \ldots, \mathrm{m}$

where:

$\mathrm{m}$ is the number of securities in the cross sectional sample, $\delta_{0}$ and $\delta_{i}$ are least squares regression coefficients and

$\widetilde{\varepsilon}$ is a random disturbance term.

Based on this adjustment procedure, the adjusted $\beta_{j 2}$ (i.e., $\hat{\beta}_{j 2}^{\prime}=\delta_{0}+\delta_{i} \beta_{j 2}$ ) is used to predict beta for the subsequent nonoverlapping period, $\beta_{j 3}$.

\section{Second Procedure}

Beta estimates are adjusted toward a mean of one ${ }^{10}$ using the following equation:

$\widehat{\beta}^{\prime \prime}{ }_{j 1}=1.0+k\left(\beta_{j 1}-1.0\right)$

where:

$\beta_{j l}$ is the estimated beta coefficient of security $j$ in period 1 ,

$k$ is a constant, common to all stocks, and

$\widehat{\beta}^{\prime \prime}{ }_{j 1}$ is the adjusted beta used to predict $\beta_{j 2}$.

\section{Third Procedure}

According to Vasicek ${ }^{11}$, and as discussed above in section I-2, information obtained from the cross sectional distribution of beta coefficient is used to adjust sample betas in keeping with a minimum expected loss criterion. This procedure makes use of the prior or historical distribution of beta coefficients. Specifically, the adjusted beta, $\hat{\beta}^{\prime \prime \prime}{ }_{j 1}$, is found as follows:

\footnotetext{
${ }^{10}$ Merrill Lynch, Pierce, Fenner, \& Smith Inc. (MLPFS) makes use of an adjustment procedure which, like Blume's predictor, is based on a cross sectional regression of historical betas for consecutive nonoverlapping time periods.

${ }^{11}$ Vasicek has suggested a Bayesian approach to the adjustment of security and portfolio betas.
} 


$$
\hat{\beta}^{\prime \prime \prime}{ }_{j 1}=\frac{\frac{\bar{\beta}_{1}}{S_{\bar{\beta} 1^{2}}}+\frac{\beta_{j 1}}{S_{\beta 1^{2}}}}{\frac{1}{S_{\bar{\beta} 1^{2}}}+\frac{1}{S_{\beta 1^{2}}}}
$$

where:

$\hat{\beta}^{\prime \prime \prime}{ }_{j 1}$ is the mean of the posterior distribution of beta for security $j$,

$\bar{\beta}_{1}$ is the mean of the cross sectional distribution of security betas for period 1 ,

$S_{\bar{\beta}} 1^{2}$ is the variance of cross sectional betas in period 1 ,

$\beta_{j 1}$ is the estimated beta coefficient for security $j$ in period 1 , and

$S_{\beta 1^{2}}$ is the variance in the estimate of $\beta_{j 1}$.

\section{MEASURING BETA COEFFICIENTS OF THE LEBANESE LISTED FIRMS}

Despite the fact that the Lebanese stock market is classified as being a pre-emerging market ${ }^{12}$, and since the Beirut Stock Exchange ${ }^{13}$ is small, not liquid, and very concentrated, there is a crucial need to found reliable studies serving as benchmarks for investors and facilitating decisions and actions to be taken in order to develop and strengthen this market. This research tries to fill this gap by building and adopting the appropriate market index that will be used for betas' calculation and adjustment.

\section{Choice Of The Market Index}

The purpose of this section is to build an index and test its efficiency in terms of reliability. Two types of indexes are developed: the Value Weighted Index (VWI) and the Price Weighted Index (PWI). Both indexes are computed on a monthly basis covering the period January 1999 - December 2003 and where 60 observations are counted. January 1999 is the base period for both indicators and the beginning value is 1000. Since the VWI is automatically adjusted, adjustment measures were introduced only for the PWI. These two indicators include all the listed firms ${ }^{14}$ during the same mentioned period. Figure 1 illustrates their trend ${ }^{15}$.

\footnotetext{
${ }^{12}$ For more details about the structure and the functioning of BSE, see Naïmy V. (2003), Marchés émergents, financement des PME et croissance économique: étude du cas libanais NDU Press. Chapter 5, pp. 261-283.

${ }^{13}$ BSE was established on the $2^{\text {nd }}$ of July, 1920. The BSE worked for 34 years without any regulations to govern its operations, until the Lebanese parliament, in 1945, enacted such a law. It was amended in 1959, 1961, 1969, and 1982. BSE closed down in 1983 as a result of the war and resumed its activity in January 1996. BSE is connected to Cairo Stock Exchange and that of Kuwait. Similarly, several agreements were concluded with Paris Stock Exchange.

${ }^{14}$ The included listed stocks are: Solidere "A", Solidere "B", B.L.C. Bank sal, Banque Audi "C", Bank of Beirut, Byblos Bank, BEMO Bank "C", Rasamny-Younis Motor Company "B", Holcim Liban, Ciments Blancs "B" (Bearer), Ciments Libanais "N" (Nominal), Uniceramic "A" (Nominal), Uniceramic "C" (bearer), and Lebanon Holdings. However, we have excluded few stocks that were de-listed or listed after the development of the index, such as: Byblos Bank Preferred Callable (listed in September 2003, BLOM Bank "GDR" (listed in November 2001), Beirut Interbank Fund (listed in November 2002), Beirut Global Income (listed in September 2003), Eternit (de-listed in March 2002), Bou Khalil Markets "B" (de-listed in December 2002).

${ }^{15}$ Values of the VWI has been divided by 100 for scaling purpose.
} 


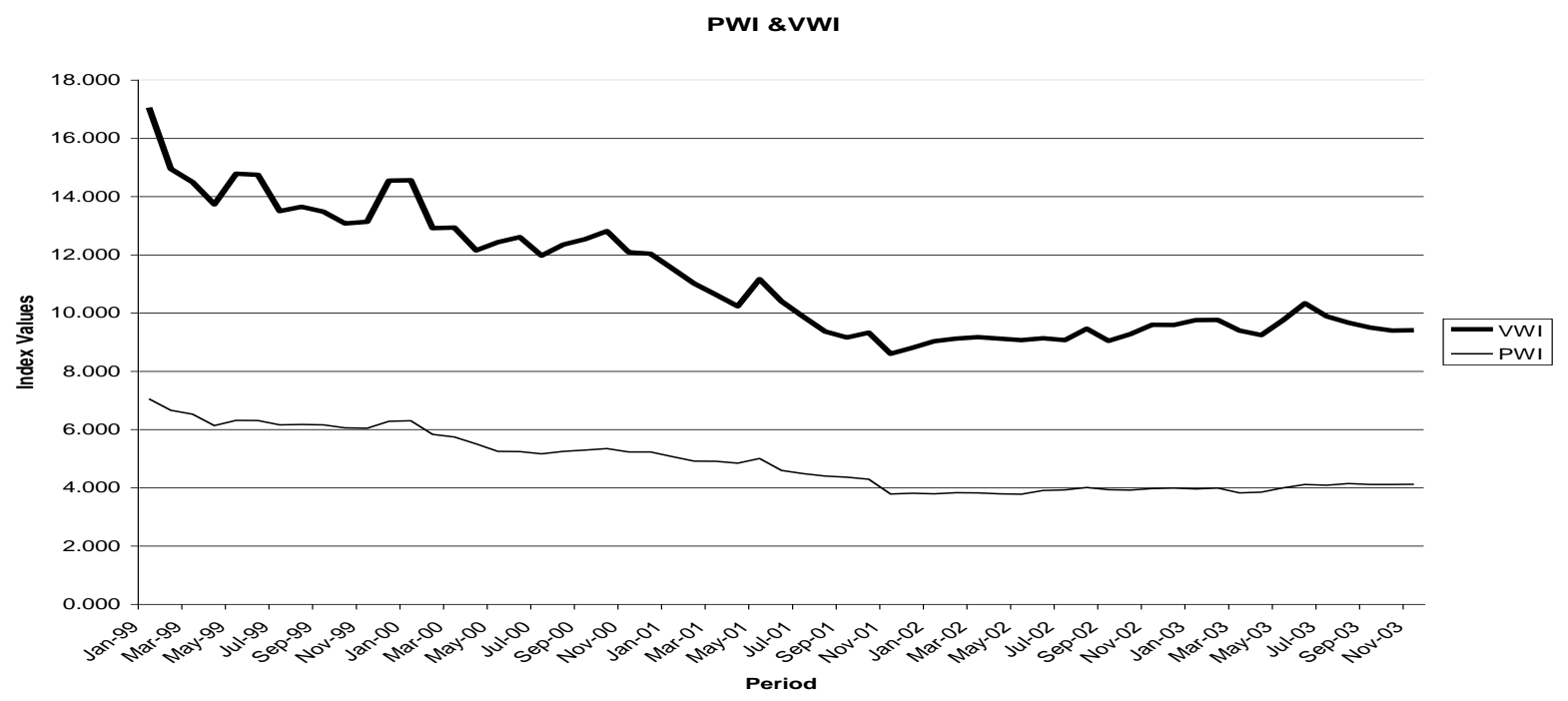

In order to select the appropriate index for beta calculation, we applied the Principle Component Analysis (PCA) method of extraction. The PCA retained only two stocks: Solidere "A" and "B" with an initial eigenvalue of $60.4 \%$ (total 8.46 ) and $17.31 \%$ (total 2.42 ) respectively, i.e., only Solidere's stock explains $77.71 \%$ of the total variability of the VWI. These figures were much more diluted when using the PWI: high correlations ${ }^{16}$ were not limited only to Solidere's stock. Consequently, the PWI seems to be more reliable and representative.

\section{Measuring And Adjusting Betas}

Equation (1) defines beta. This equation represents also the slope coefficient in a regression of the stock return against the market return. The market returns are defined as the percentage monthly price change of the above selected price index. Table 1 depicts the regression results for calculating Beta using 60 observations.

Since the Lebanese stock market is relatively "young", the adjustment procedures as discussed above cannot be properly applied, i.e., cross sectional analysis are impossible. Consequently, and in order to overcome this constraints, we conceived the following procedure for an optimal beta forecasting:

- $\quad$ Application Of A Specific Evaluation Model To Adjust The Statistical Calculated Beta (as shown in table 1). The above computed betas are not significantly representatives of historical betas because of the BSE's conditions ${ }^{17}$ since its re-opening. Hence, according to our new evaluation model, historical beta, $\beta_{\mathrm{h}}$, will be the average of the statistical beta, $\beta_{\mathrm{s}}$, and the corresponding adjusted one, $\beta$ '.

$\beta_{\mathrm{h}}=\left(\beta_{\mathrm{s}}+\beta^{\prime}\right) / 2$

\begin{tabular}{|c|c|c|c|c|c|c|c|c|c|c|c|c|c|c|c|}
\hline & 衣 & 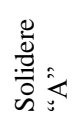 & 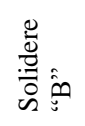 & 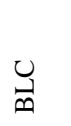 & 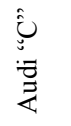 & 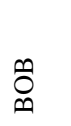 & 莡 & $\sum_{\substack{i=1 \\
0}}^{0}$ & 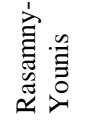 & 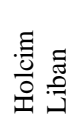 & 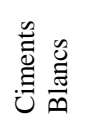 & 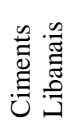 & 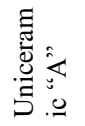 & 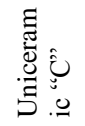 & 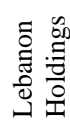 \\
\hline PWI & 1.00 & 0.93 & 0.93 & 0.93 & 0.95 & -0.53 & 0.85 & 0.66 & 0.90 & 0.23 & 0.31 & -0.77 & 0.53 & -0.84 & 0.85 \\
\hline
\end{tabular}

${ }^{17}$ Small market, non-liquid, and prices fluctuation are not representative. For more details see Naïmy V. (2003). 
Table 1: Beta Coefficient Of The Listed Lebanese Firms, $\mathbf{B}_{\mathrm{s}}$.

\begin{tabular}{|c|c|c|c|c|c|}
\hline & $\begin{array}{c}\text { Beta Coefficient } \\
\beta_{s}\end{array}$ & R Square & $\begin{array}{c}\text { Probability of } \\
\text { t Statistic }\end{array}$ & $\begin{array}{c}\text { Lower } 95 \% \\
\text { Confidence } \\
\text { Level }\end{array}$ & $\begin{array}{c}\text { Upper 95\% } \\
\text { Confidence } \\
\text { Level } \\
\end{array}$ \\
\hline $\begin{array}{c}\text { Solidere "A" } \\
\text { (Sldr A) }\end{array}$ & 1.79 & 0.315 & $4.56 \mathrm{E}-06$ & 1.08 & 2.5 \\
\hline $\begin{array}{l}\text { Solidere "B" } \\
\text { (Sldr B) }\end{array}$ & 1.57 & 0.26 & $4.23 \mathrm{E}-05$ & 0.86 & 2.28 \\
\hline $\begin{array}{c}\text { B.L.C. Bank sal } \\
(\mathrm{Blc})\end{array}$ & 1.95 & 0.382 & $2.33 \mathrm{E}-07$ & 1.28 & 2.61 \\
\hline $\begin{array}{c}\text { Banque Audi "C" } \\
\text { (Audi) }\end{array}$ & 1.09 & 0.369 & $4.23 \mathrm{E}-07$ & 0.70 & 1.47 \\
\hline $\begin{array}{l}\text { Bank of Beirut } \\
\text { (Bob) }\end{array}$ & 0.013 & 0.0054 & 0.581 & -0.034 & 0.06 \\
\hline $\begin{array}{c}\text { Byblos Bank } \\
\text { (Byb) }\end{array}$ & 0.458 & 0.018 & 0.302 & -0.423 & 1.341 \\
\hline $\begin{array}{c}\text { BEMO Bank "C" } \\
\text { (Bemo) }\end{array}$ & 0.269 & 0.051 & 0.087 & -0.040 & 0.579 \\
\hline $\begin{array}{c}\text { Rasamny-Younis } \\
\text { Motor Company } \\
\text { "B" (RY) }\end{array}$ & 0.066 & 0.00 & 0.817 & -0.510 & 0.643 \\
\hline $\begin{array}{l}\text { Holcim Liban } \\
(\mathrm{Hlcm})\end{array}$ & 0.328 & 0.014 & 0.368 & -0.397 & 1.053 \\
\hline $\begin{array}{l}\text { Ciments Blancs } \\
\text { "B" (CB) }\end{array}$ & 0.174 & 0.005 & 0.586 & -0.465 & 0.815 \\
\hline $\begin{array}{c}\text { Ciments Libanais } \\
\text { "N" (CL) }\end{array}$ & 0.0164 & 0.00 & 0.868 & -0.182 & 0.215 \\
\hline $\begin{array}{c}\text { Uniceramic “A” } \\
\text { (Uni A) }\end{array}$ & 0.312 & 0.035 & 0.156 & -0.123 & 0.749 \\
\hline $\begin{array}{c}\text { Uniceramic "C" } \\
\text { (Uni B) }\end{array}$ & 0.129 & 0.032 & 0.174 & -0.058 & 0.317 \\
\hline $\begin{array}{c}\text { Lebanon } \\
\text { Holdings (LH) } \\
\end{array}$ & 0.652 & 0.048 & 0.097 & -0.122 & 1.427 \\
\hline
\end{tabular}

This model uses actual historical returns.

- $\quad$ Adjusting Historical Betas, $\beta_{h}$, Using An Implicit Prediction Equation For Future Betas, $\beta_{a}$. This adjustment suggests the calculation of the industry's beta. Thus, it makes more sense to adjust the historical beta of a given firm toward the corresponding beta of its industry than toward a value of $1.0^{18}$. Consequently, adjusted beta becomes:

$$
\beta_{\mathrm{a}}=\alpha \beta_{\text {ind }}+b \beta_{\mathrm{h}}
$$

where $a$ and $b$ are positive constants that sum to 1.0 and $\beta_{\text {ind }}$ denotes the average equity beta of the industry to which the stock belongs.

\section{Calculation Of $\beta$ '}

Based on explicit criteria affecting the performance of the concerned firm, we suggest the allocation of a weight factor ${ }^{19}$ to each criterion varying between 1 and 5 . Likewise, a risk degree ${ }^{20}$ is assigned to the concerned

\footnotetext{
${ }^{18}$ As published in the Value Line Investment Survey; their adjusted beta is equal to $(.35 \mathrm{x} 1.0)+(.67 \mathrm{x} \beta \mathrm{h})$. See Reilly F. and Wright D., (1988), “A Comparison of Published Betas", Journal of Portfolio Management, 14, no. 3, Spring, pp. 64-69.

19 The weight factor depends on the importance of the concerned criterion. In our example, the weight has been determined based on an empirical study that we have conducted on six firms belonging to the same sector. The weight was by itself a weighted average of the corresponding weights allocated by each firm of the sample.
} 
criterion and each risk degree is graded. Consequently, the final beta is represented by the sum of the weighted criteria multiplied by the corresponding assigned degree of risk. For illustration, table 2 shows the details of beta calculation of the listed Lebanese firm Solidere.

Table 2: Beta Coefficient Using A Qualitative/Quantitative Adapted Model For Solidere Firm

\begin{tabular}{|c|c|c|c|c|c|}
\hline \multirow{2}{*}{ Selected Criteria } & \multirow[b]{2}{*}{$\begin{array}{c}\text { Weight } \\
(1-5)\end{array}$} & \multicolumn{3}{|c|}{ Degree of Risk } & \multirow[b]{2}{*}{ Total } \\
\hline & & $\begin{array}{l}\text { Low } \\
(0.5) \\
\end{array}$ & $\begin{array}{l}\text { Average } \\
\text { (1) }\end{array}$ & $\begin{array}{l}\text { High } \\
(1.5) \\
\end{array}$ & \\
\hline Economic Risk & 9 & & & & \\
\hline Macro Economic Risk & 4 & & & $\mathrm{x}$ & 6 \\
\hline Political Risk & 5 & & & $\mathrm{x}$ & 7.5 \\
\hline Market Risk & 8 & & & & \\
\hline Construction Market & 3 & & & $\mathrm{x}$ & 4.5 \\
\hline Competition & 2 & & & $\mathrm{x}$ & 3 \\
\hline Relationship with the government & 3 & & & $\mathrm{x}$ & 4.5 \\
\hline Operational Risk & 12 & & & & \\
\hline Legal Procedures & 5 & & & $\mathrm{x}$ & 7.5 \\
\hline Construction & 3 & & & $\mathrm{x}$ & 4.5 \\
\hline Development of Business & 3 & & $\mathrm{x}$ & & 3 \\
\hline Infrastructure Work & 2 & $\mathrm{x}$ & & & 1 \\
\hline Other & 2 & & $\mathrm{x}$ & & 2 \\
\hline Total & 29 & & & & 43.5 \\
\hline$\beta^{\prime}$ & 1.5 & & & & \\
\hline
\end{tabular}

The same methodology is applied for each listed firm. Table 3 illustrates the values of $\beta$ ' and the final historical adjusted beta of each firm.

Table 3: Adjusted Historical Betas

\begin{tabular}{|c|c|c|c|c|c|c|c|c|c|c|c|c|c|c|}
\hline ڤึ & $\dot{\bar{t}} \varangle$ & $\dot{\bar{\sigma}} \oplus$ & $\frac{\ddot{\theta}}{\theta}$ & 㫣 & คे & $\overrightarrow{\hat{A}}$ & ڤ્ڤ & $\approx$ & 豆 & ยै & $\overrightarrow{0}$ & 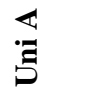 & $\stackrel{U}{\cdot \Xi}$ & $\underline{3}$ \\
\hline$\beta_{\mathrm{s}}$ & 1.79 & 1.57 & 1.95 & 1.09 & 0.013 & 0.458 & 0.269 & 0.066 & 0.328 & 0.174 & 0.016 & 0.312 & 0.129 & 0.652 \\
\hline$\beta$, & 1.5 & 1.5 & 1.2 & 1.1 & 1.3 & 1.1 & 1.4 & 1.2 & 1.1 & 1.2 & 1.1 & 1.2 & 1.2 & 1.3 \\
\hline$\beta_{\mathrm{h}}$ & 1.64 & 1.53 & 1.57 & 1.09 & 0.65 & 0.77 & 0.83 & 0.63 & 0.71 & 0.68 & 0.55 & 0.75 & 0.66 & 0.97 \\
\hline
\end{tabular}

\section{Calculation Of $\boldsymbol{\beta}_{\mathbf{a}}$}

Applying equation (12) requires the estimation of $\beta_{\text {ind }}$. For this purpose we have conducted an empirical study covering the five largest firms in each industry in order to determine the average equity betas ${ }^{21}$ for stocks in various industry classifications. The Lebanese listed firms belong to 5 different industries. Table 4 represents average values of beta for stocks in these industries.

\footnotetext{
${ }^{20}$ Low, average, and high risk.

${ }^{21}$ Beta estimation of each of the top 5 firms belonging to the corresponding industry was done with respect to our conceived method developed in table 2 .

Previous studies are already done on some of these industries, see

Naïmy V. (2004). "Financing Problems Faced By The Lebanese SMEs: An Empirical Study". The International Business And Economics Research Journal, Volume 3, Number 1, January, pp. 27-38, and “Overall Lebanese Banks' Performance: A RiskReturn Framework”. The International Business And Economics Research Journal, Volume 4, Number 1, January 2005, p. 1-10.
} 
Table 4: Average Values Of $B_{\text {ind }}$

\begin{tabular}{|c|c|}
\hline Industry & Beta Value \\
\hline Construction & 1.5 \\
\hline Motor Vehicles & 1.37 \\
\hline Banks & 0.95 \\
\hline Investment services & 1.28 \\
\hline Manufacturing & 1.43 \\
\hline
\end{tabular}

Considering a value of .35 and .65 for $a$ and $b$ respectively ${ }^{22}$, equation (12) indicates that this procedure takes the historical beta for a security and adjust it by giving it a value approaching the one of its industry. Table 5 displays the outputs of equation (12).

Table 5: Final Adjusted Beta

\begin{tabular}{|c|c|c|c|c|c|c|c|c|c|c|c|c|c|c|}
\hline$\stackrel{\mathscr{E}}{\tilde{E}}$ & $\underset{i}{\overleftarrow{5}}$ & $\stackrel{\infty}{5}$ & $\frac{e}{a}$ & $\bar{\Xi}$ & $\stackrel{\overrightarrow{0}}{0}$ & $\overrightarrow{\hat{\theta}}$ & 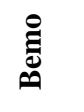 & $\approx$ & $\stackrel{\Xi}{\Xi}$ & טै & $\bar{v}$ & $\underset{\Xi}{\sharp}$ & $\stackrel{U}{\mathscr{G}}$ & $\Xi$ \\
\hline $\mathrm{B}_{\mathrm{a}}$ & 1.59 & 1.52 & 1.35 & 1.04 & 0.75 & 0.83 & 0.87 & 0.89 & 0.96 & 0.94 & 0.86 & 0.99 & 0.93 & 1.08 \\
\hline
\end{tabular}

\section{Validity Of The Conceived Adjusted Beta}

In order to test the efficiency of our suggested procedure regarding beta adjustment or beta forecast, we need to compare ex ante and ex post beta values for the same studied firms. But since BSE took up again its activity since 1996, there is no way for comparison. Nonetheless, these figures constitute a solid base for future assessment regarding the accuracy of our suggested adjustment procedure.

\section{CONCLUSION}

This study constitutes a base and a reliable springboard for any potential analysis related to the performance of the Lebanese stock market. We demonstrated that the PWI is more representative than the VWI since the latter is dominated up to $77 \%$ by one firm. Betas of all listed firms were measured. We have also conceived a particular adjustment procedure aiming, in the first place, at adjusting the statistical beta by applying a specialized model quantifying beta based on criteria related to the firm's business. Then, a fair weighted distribution was allocated to the new adjusted historical beta and to the average beta of the corresponding industry in order to get the final adjusted beta. Testing the consistency of these values as being a good proxy for a better forecasted beta is not possible for the time being because of the very limited available number of years since the reopening of BSE. Consequently, these results will serve as a foundation for future application of the Blume's predictor and the Bayesian approach.

\section{BIBLIOGRAPHY}

1. Amihud, Y. and Mendelson, H. (1986), Asset Pricing and Bid-Ask Spread, Journal of Financial Economics, Vol. 17, No.2, December, pp. 223-249.

2. Amihud, Y. and Mendelson, H. (1986), Liquidity and Stock Returns, Financial Analyst Journal, Vol. 42 , N0. 3, May/June, pp 43-48.

3. Amihud, Y. and Mendelson, H. (1991), Liquidity, Asset Prices, and Financial Policies, Financial Analyst Journal, Vol. 47, No. 6, November/December, pp. 56-66.

4. Beirut Stock Exchange Monthly Bulletins.

\footnotetext{
${ }^{22}$ We allocate $35 \%$ weight to the average industry beta and $65 \%$ weight to the historical adjusted estimate of beta for each stock. These weights are selected in conformity with many previous studies, such as the Value Line Investment and the Merrill Lynch studies, etc.
} 
5. Beirut Stock Exchange Website (www.bse.com.lb).

6. $\quad$ Blume, M. (1971), On The Assessment of Risk, The Journal Of Finance, March, pp. 1-10.

7. Central Bank Website (www.bdl.gov.lb).

8. Elton, E. and Gruber, M. (1973), Estimating the Dependence Structure of Share Prices, The Journal Of Finance. December. pp. 1203-1232.

9. Elton, E., Gruber, M., and Urich, T., (1978), Are Betas Best?, The Journal Of Finance, December, Volume 33, No. 5, December, pp. 1375-1384.

10. Fama, E. and French, K. (1996), The CAPM Is Wanted Dead or Alive, Journal Of Finance, Vol. 51, No. 5, December, pp. 1947-1958.

11. Fisher, L. and Kamin, J., (1991), Good Betas and Bad Betas, Paper for the Seminar on the Analysis of Security Prices, University of Chicago.

12. Jegadeesh, N. and Titman, S. (1993), Returns to Buying Winners and Selling Losers: Implications for Stock Market Efficiency, The Journal of Finance, March, pp. 69-91.

13. Naïmy, V. (2003), Marchés émergents, financement des PME et croissance économique: étude du cas libanais, NDU Press, pp. 261-283.

14. Naïmy, V. (2004), Financing Problems Faced By The Lebanese SMEs: An Empirical Study. The International Business And Economics Research Journal, Volume 3, Number 1, January, pp. 27-38.

15. Naïmy, V. (2005), Overall Lebanese Banks' Performance: A Risk-Return Framework. The International Business And Economics Research Journal, Volume 4, Number 1, January, p. 1-10.

16. Odean, T. (1998), Are Investors Reluctant To Realize Their Losses?, Journal Of Finance, October. pp. 17751798.

17. Reilly, F. and Wright, D., (1988), A Comparison of Published Betas, Journal of Portfolio Management, Vol. 14, no. 3, Spring, pp. 64-69.

18. Vascicek, O., (1973), A Note on Using Cross-Sectional Information in Bayesian Estimation of Security Betas, The Journal Of Finance, December, pp. 1233-1239.

19. Ziebart, D., (1985), Control of Beta Reliability in Studies of Abnormal Return Magnitudes: A Methodological Note, The Journal of Accounting Research, Volume 23, No. 2, Autumn, pp. 920-926. 


\section{NOTES}

